\title{
License prices for financially constrained firms
}

\author{
Roberto Burguet • R. Preston McAfee
}

(C) The Author(s) 2009. This article is published with open access at Springerlink.com

\begin{abstract}
It is often alleged that high auction prices inhibit service deployment. We investigate this claim under the extreme case of financially constrained bidders. If demand is just slightly elastic, auctions maximize consumer surplus if consumer surplus is a convex function of quantity (a common assumption), or if consumer surplus is concave and the proportion of expenditure spent on deployment is greater than one over the elasticity of demand. The latter condition appears to be true for most of the large telecom auctions in the US and Europe. Thus, even if high auction prices inhibit service deployment, auctions appear to be optimal from the consumers' point of view.
\end{abstract}

Keywords Financing constraints - 3G auctions - Licenses - Budget constraints · Service deployment · Rollout

JEL Classifications L51 $\cdot$ D45

\author{
R. Burguet $(\varangle)$ \\ Institute for Economic Analysis (CSIC) Campus UAB, \\ 08193 Bellaterra, Barcelona, Spain \\ e-mail: roberto.burguet@iae.csic.es \\ R. P. McAfee \\ California Institute of Technology, Pasadena, CA 91125, USA \\ e-mail:mcafee@caltech.edu \\ R. P. McAfee \\ Yahoo! Inc, Burbank, CA, USA
}


"It is a victory for consumerism and common sense".

Etain Doyle, Director of Ireland's regulator ComReg (then Telecommunications Regulation), commenting the decision to award $3 \mathrm{G}$ Irish licenses through a "beauty contest". 1

\section{Introduction}

It is often alleged that high auction prices for spectrum licenses have inhibited the deployment of related services, to the detriment of consumers. For example, telecom specialist John Tennant said that the bids on the third generation, or $3 \mathrm{G}$, licenses increased the cost of debt service to the point that the companies could not borrow for infrastructure development, and ultimately accounts for the dramatic drop in share prices of the telecom sector (McCleland 2003) Similarly, an EC report studying 3G services identifies the $€ 110$ billion paid for licenses as a major constraint on investment. Several nations, including Finland, Ireland, Spain and Sweden, awarded 3G licenses for low prices not set by auction, using what are often called "beauty contests," ostensibly because this would lead to a faster deployment of services (Commission of the EC 2002). Dr. Keiji Tachikawa, president of Japan's largest cellular company (NTT DoCoMo), agrees:

"Operators will have to pass on the added cost [of auctioned licences] to consumers. This could be a hurdle for the spread of $3 \mathrm{G} . ", 2$

We investigate the properties of auctions, from a perspective of consumer welfare, under the extreme assumption that the bidders face salient financing constraints. This makes it theoretically possible for the critics to be right, that financing constraints inhibit the deployment of services. We show that auctions still maximize consumer surplus, including license revenue, provided the elasticity of demand is above certain threshold.

Textbook economic analysis suggests that license prices are sunk costs by the time investment decisions are made, and thus should have no effect on the deployment of services. Moreover, if profitability of deployment varies across countries, one might expect the high profitability countries to attract both high auction prices and rapid and extensive deployment to capture the high profitability, inducing a positive correlation between auction prices and service deployment. Even if profitability is constant, the fallacy of sunk costs suggests, in addition, that psychologically the managers should want to invest more in the regions with high-priced licenses, not less.

On the other hand, starting with Jensen (1986) free cash flow concepts, modern corporate finance emphasizes the importance of restraining managers by limiting their ability to invest. Moral hazard, in the form of career concerns or limited liability, can induce managers to take excess risks. The natural response to such managerial

\footnotetext{
1 Auctions: A License To Bill? by Nicki Hayes, http://www.wirelessdevnet.com/channels/wireless/ features/licensetobill.html, last visited May 22nd, 2006.

2 Business Week, October 16, 2000, p. 25.
} 
problems is to limit the ability of the manager to make bad choices, either by imposing a budget constraint on the manager, or requiring the manager to use a much higher discount factor than the actual average cost of capital for a project under consideration. Even if budgets are "soft," in the sense that there is always more money possible, individual executives may bear a career cost of asking for more money, perhaps because they are seen as having mis-estimated the costs, making them hesitate to request more money unless the gains are very large. Such a situation mirrors a financing constraint, at least for some realizations of costs.

The recognition that agency problems - either moral hazard or asymmetric infomation or both-might have an impact on corporate financing and investment probably begins with Stiglitz and Weiss (1981), which argues that asymmetric information can impede credit markets, and Greenwald et al. (1984), which argues that equity financing does not cure the agency problem created by asymmetric information. Other theoretical justifications leading to financing constraints and inflexible rules include Myers and Majluf (1984); Lewis and Sappington (1989a,b); Greenwood and McAfee (1991); Hart and Moore (1995) and Clementi and Hopenhayn (2006). Overall, the thrust of the theoretical literature is that budget or financing constraints imposed on firm managers play an important role in ameliorating incentive problems.

Many empirical tests corroborate the existence of financial constraints by showing that internal and external financing are not perfect substitutes. The theme of the empirical studies is that investment decisions are affected by the amount of cash on hand. Significant studies include Fazzari and Athey (1987), Fazzari et al. (1988), Whited (1992); Fazzari and Petersen (1993) and Love (2003). There seems to be wide acceptance in the corporate finance literature that financial constraints are very real and relevant even to telecom-sized firms, especially in situations where information is imperfect.

The behavior of the telecom industry during the 1990s reinforces the importance of managerial incentive problems. Some companies bid in excess of the maximum values suggested by their own analyses. For example, Stefan Zehle describes a $3 G$ bidder in the UK who bid $£ 5$ billion for a license that the company estimated was worth $£ 1$ billion (McCleland 2003). He also describes an executive who called the auctions a "spectrum landgrab" and that the bidders should not worry whether the prices made business sense (McCleland 2003). ${ }^{3}$ One author (McAfee) was repeatedly asked by spectrum bidders for auction-theoretic reasons for bidding in excess of the net present value. The managers were very disappointed to hear about the winner's curse, which goes in the other direction, encouraging lower, more conservative bids. ${ }^{4}$ In addition, many of the bidders believed that other bidders faced financing constraints and consulted with economists in an attempt to estimate just what those constraints might

\footnotetext{
3 For an opposing view of the European 3G auctions, see Klemperer (2002).

4 The likely reason for this tendency to bid in excess of net present value was the 1980s experience. The actual number of U.S. cell phone users in 1990 was ten times the expectation projected in 1980 for 1990 , and cellular profits represented a large fraction of total telecom profits, mostly because there were only two firms in most regions and limited capacity. This dramatic underestimate of the value of wireless fueled an unjustified optimism.
} 
be. J. Bulow et al. (Unpublished manuscript, 2008) and Salant (1997) corroborate the existence of budget constraints in telecom auctions.

In a world of possibly financially constrained firms, do auctions maximize consumer surplus, counting the revenue raised by the auction as part of consumer surplus? ${ }^{5} \mathrm{We}$ characterize conditions under which auctions yield an optimal price from the perspective of consumers, in spite of the presence of binding financing constraints.

Rather than explicitly consider auctions, we consider a posted price, which simplifies the analysis. This price may range from zero to a maximum where the firms earn zero profits. Generally the zero profit point is the price that would emerge from an auction among symmetric firms; financing constraints are salient if they strictly bind at this price.

If the elasticity of demand, $\varepsilon$, exceeds $1+1 / n$ evaluated at the (Cournot) unconstrained output, where $n$ is the number of licenses, then the price where financing constraints just bind falls short of the consumer surplus-maximizing price. In fact, if the consumer surplus is convex in output (a case which arises with linear demand) then the consumer-surplus maximizing price is always the auction price. If consumer surplus is concave (e.g. constant elasticity of demand), then $\varepsilon$ exceeding $1+1 / n$ is a necessary condition for auctions to be optimal. A sufficient condition in this instance is that no more than $(\varepsilon-1) / \varepsilon$ of the budget is spent on the licenses.

The formulas we derive are well rooted in economic analysis, e.g. they are the natural counterpart of Ramsey pricing in the regulation of natural monopoly. In addition, they have the virtue of being simple and implementable. In particular, in the United States PCS auctions, licenses costs were estimated somewhere between $20 \%$ and $40 \%$ of the costs of deploying a PCS service. ${ }^{6}$ Even if the firms were financially constrained, and even if consumer surplus was concave, an auction was consumer surplus-maximizing provided the elasticity of demand for PCS services exceeded 1.66. We argue in Sect. 5 that the demand for new wireless services is elastic. ${ }^{7}$ Under that assumption, even if the critics are right that auctions curtail output (deployment) relative to beauty contests, auctions nonetheless are in the best interest of consumers.

Auctions have an important advantage that is not considered in this paper-auctions tend to pick the most able companies. By assuming no efficiency differences between our firms, we set aside this advantage and provide a stronger case for using

\footnotetext{
5 Auctions with budget constraints have been examined by C. Pitchik and Schotter (Unpublished manuscript, 1986), Pitchik and Schotter (1988); Che and Gale (1998), and Benoit and Krishna (2001). The focus of these papers is on the firms' ability to bid in subsequent auctions, given the prices paid in earlier auctions, and on the proposition that bidders might artificially inflate the price of earlier sales as a means of reducing the ability of the winners to pay for later items. In contrast, we examine the ability of firms to deploy a service after the sale. Haan and Toolsema (2003) introduce credit rationing due to market uncertainty and limited liability in a model of license allocation, providing an alternative source of "budget constraints". In their model, higher nominal interest rates (debt burden) induce firms to take a more aggressive behavior in the market, due to the assumption that uncertainty is resolved after market competition.

6 Salant (1997), reporting on his experience selecting the bidding strategy of GTE, estimates expected buildout cost to be easily two or three times the license payments.

7 Over the rollout of PCS services, prices have dropped by $50 \%$ or so, and the number of customers has grown by at least several hundred percent, suggesting elasticities over 4. However, the technology has changed substantially as well, with smaller phones with many more features like cameras and instant messaging, which may account for some of the increased sales.
} 
beauty contests, since reducing the advantages of auctions makes our conclusion that auctions are nonetheless optimal even stronger. In general, the model is stylized for clarity but we anticipate the effects identified to carry over to more elaborate settings, although of course new phenomena may arise in such settings. In addition, auctions have a reduced informational requirement relative to the posted price we consider, but our price mechanism implements the same outcome.

The paper proceeds as follows. The second section develops the basic Cournot theory and the third section proves the main results. The fourth section shows that auctions indeed result in the zero profit price, when this price is unique, and shows that the theory is robust to asymmetries in the budget. In that section we also discuss how our results are affected when the government's objective function puts a positive weight on firms' profits or the shadow cost of public funds is positive. The fifth section considers the application of the theory to the European experience with $3 \mathrm{G}$ services. The sixth section concludes.

\section{The model}

There are $n$ licenses, and at least $n+1$ identical firms. A license is a right to compete in a symmetric Cournot industry. ${ }^{8}$ We discuss below alternative assumptions (e.g., price competition). If industry output is $Q$, then the realized price is $p(Q)$.

The elasticity of demand is

$$
\varepsilon(Q)=\frac{-p(Q)}{Q p^{\prime}(Q)}
$$

Where the risk of confusion is minimal, we will suppress the dependence of $\varepsilon$ on $Q$. We assume that for all $Q$,

$$
2 p^{\prime}(Q)+Q p^{\prime \prime}(Q)<0 \text {. }
$$

Inequality (2) is the condition that marginal revenue is downward sloping, and insures that the second order conditions hold globally for Cournot equilibrium.

Let $\lambda$ be the price of a license, and $B$ the budget of each firm. We model the financing constraint as a "hard" budget constraint, primarily to favor the case that

\footnotetext{
${ }^{8}$ We assume the Cournot model not because it is necessarily the best model of any specific industry but primarily for its tractability, and because we consider that the deployment in cellular is a capacity choice which is best modeled by Cournot. Using the homogeneous-good, Cournot model makes our analysis comparable to many other regulation studies, and has the added advantage that the effects of budget constraints have a natural interpretation in the Cournot model. In contrast, in a differentiated products model, the effects of budget constraints could be to limit capacity but could also affect the dissimilarity of the products. In addition, differentiated product models are notoriously challenging to analyze. However, the analysis of such models represents the natural next step. Competition among cellular telephone companies has both a quantity and a differentiated product aspect. For part of their history, the cell companies have been capacity constrained, and these capacity constraints are alleviated by the denser deployment of towers. With respect to $3 \mathrm{G}$ services, however, differentiation is an important aspect of competition, although even there, investments needed to deploy any $3 \mathrm{G}$ services were slow in coming.
} 
financing constraints might interfere with subsequent production. That is, "soft" budget or financing constraints are generally going to have less of an effect than "hard" financing constraints. Also, as we will show in the next section, if firms are asymmetrically constrained the case for auctions is actually stronger. If a firm chooses to produce the quantity $q$, the constraint becomes

$$
c q+\lambda \leq B
$$

where $c$ is the marginal cost of output. Apart from variable costs, there may be other fixed costs. Our model readily allows for this possibility with only interpreting $\lambda$ as the license price plus these fixed costs. We assume that $c$ is below the demand price $p(Q)$ for some positive quantity $Q$.

We look for a symmetric equilibrium in output. Suppose the symmetric equilibrium quantity choice is $q^{*}$. Each firm's profits are

$$
\pi_{i}=\max _{c q+\lambda \leq B} p\left(q+(n-1) q^{*}\right) q-c q-\lambda .
$$

We first consider the quantity choices of the firms, which are characterized in Lemma 1.

Lemma 1 There is a unique Cournot equilibrium, and it is symmetric and has industry output $Q$ satisfying:

$$
p(Q)\left(1-\frac{1}{n \varepsilon(Q)}\right)-c \begin{cases}=0 & \text { if } c Q / n+\lambda<B \\ \geq 0 & \text { if } c Q / n+\lambda=B\end{cases}
$$

All proofs are contained in the Appendix.

When the financing constraint does not bind, condition (5) can be expressed as

$$
p(Q)=\frac{n \varepsilon}{n \varepsilon-1} c .
$$

The solution to (6) is the unconstrained Cournot outcome. Let $Q_{c}$ be this solution. The associated profits are

$$
\pi=p\left(Q_{c}\right) \frac{Q_{c}}{n}-c \frac{Q_{c}}{n}-\lambda=\left(\frac{n \varepsilon}{n \varepsilon-1}-1\right) c \frac{Q_{c}}{n}-\lambda=\frac{1}{n} \frac{c Q_{c}}{n \varepsilon-1}-\lambda .
$$

If the financing constraint binds,

$$
p\left(n \frac{B-\lambda}{c}\right) \geq \frac{n \varepsilon}{n \varepsilon-1} c
$$

and profits are

$$
\pi=p\left(n \frac{B-\lambda}{c}\right) \frac{B-\lambda}{c}-c \frac{B-\lambda}{c}-\lambda=p\left(n \frac{B-\lambda}{c}\right) \frac{B-\lambda}{c}-B .
$$


We assume that license prices will have to satisfy voluntary participation of firms. The maximum that any firm would pay for a license is a level leading to zero profits. We denote the zero-profits license price by $\lambda_{0}$ :

$$
\lambda_{0}=(p(Q)-c) \frac{Q}{n}
$$

We will discuss in Sect. 4 the existence and uniqueness of this price and why this is the price an auction would fetch. For the moment, assume it is indeed unique.

\section{Optimal prices}

What is the optimal license price $\lambda$ ? Different license prices induce different consumer surplus, profits for the firms, and revenues for the government. Thus, the answer to our question will depend on the relative weights of these components on the objective function of the government. In this section we consider the goal of the government to be maximizing consumer surplus plus license revenue. This is probably the most realistic objective function for regulators in general. ${ }^{9}$ More relevant to our particular problem, this is an objective function that better fits declared intentions of governments when assigning telecommunication license. ${ }^{10}$ In the next section we discuss how our (quantitative) results change when the government assigns a positive weight to firms' profits.

Thus, the objective function for the government is

$$
C S+R=\int_{0}^{Q}(p(x)-p(Q)) \mathrm{d} x+n \lambda .
$$

$\mathrm{CS}$ (and then CS+R) is a convex function of output when

$$
p^{\prime}(Q)+Q p^{\prime \prime}(Q)<0
$$

Note that (12) guarantees the second order condition (2). CS is convex whenever a tax on a monopoly is only partially passed on to consumers, which is a common assumption. The condition (12) is satisfied by concave, and in particular linear demand.

\footnotetext{
${ }^{9}$ We assume the shadow cost of public funds to be 1 . In fact, our results would be strengthened under the more plausible, standard hypothesis that this cost is above 1. See Sect. 4 below. In the $3 \mathrm{G}$ case, and interpreting $\mathrm{Q}$ as size of network, there is an additional redistributive issue between different consumers, particularly between those living in more densely populated areas, where deployment would be faster, and those in less populated areas, where the cuts would be most likely to happen. We thank a referee for pointing this out.

${ }^{10}$ For instance, for the British government, the main goal was the "efficient utilisation of the spectrum and the enhancement of competition between operators to the benefit of consumers." (page 6 of The Auction of Radio Spectrum for the Third Generation of Mobile Telephones, Report by the Comptroller and Auditor General, October 1991 http://www.nao.org.uk/intosai/wgap/0102233.pdf). Revenue, although less openly recognized, was also welcomed.
} 
Denote the level that leads to the financing constraint just binding by $\lambda_{B}$. Note that $\lambda_{B}$ is defined by

$$
n \frac{B-\lambda_{B}}{c}=Q_{c}
$$

For values of $\lambda<\lambda_{B}, \mathrm{CS}$ is (locally) independent of $\lambda$. Indeed, firms are effectively unconstrained, and their output will be equal to the Cournot output. For $\lambda>\lambda_{B}$, (13) is the expression of output as a function of $\lambda$, for general values of $Q$ and $\lambda$. Thus,

$$
\frac{\mathrm{d}(C S+R)}{\mathrm{d} \lambda}= \begin{cases}\frac{n}{c}\left(Q \frac{\mathrm{d} p(Q)}{\mathrm{d} Q}+c\right)=\frac{n}{c}\left(c-\frac{p(Q)}{\varepsilon(Q)}\right) & \text { if } \lambda>\lambda_{B} \\ n & \text { if } \lambda<\lambda_{B}\end{cases}
$$

and $\mathrm{CS}+\mathrm{R}$ is increasing for $\lambda<\lambda_{B}$. Thus, a sufficient condition for optimal prices to be strictly larger than $\lambda_{B}$ is that $c-\frac{p}{\varepsilon}>0$ at $\mathrm{Q}_{c}$. But at that level of output, (5) is just satisfied with equality and any reduction in quantity would violate (5). Therefore,

Lemma 2 The value of $\lambda$ that maximizes $C S+R$ is at least $\lambda_{B}$. If $\varepsilon\left(Q_{c}\right)>\frac{n+1}{n}$, then the $C S+R$-maximizing value of $\lambda$ exceeds $\lambda_{B}$.

For sufficiently elastic demand (evaluated at the Cournot quantity), an optimal license price should cause the financing constraints to bind, if at that price firms earn positive profits. If $\lambda_{B}>\lambda_{0}$, an auction maximizes consumer surplus, since the financing constraint is not salient (at all prices that firms voluntarily agree to pay, firms are not financing constrained). The interesting case is when $\lambda_{B}<\lambda_{0}$. In this case, should the government attempt to extract the highest possible price for the licenses?

$\mathrm{CS}+\mathrm{R}$ is convex in $\lambda$ for $\lambda>\lambda_{B}$ if CS is convex in output (because (3) holds with equality). Thus, in this case we can conclude immediately from Lemma 2 that $\lambda_{0}$ is indeed the optimal price if the conditions of that lemma are satisfied. If CS+R is increasing at $\lambda_{B}$ it is also increasing at any $\lambda>\lambda_{B}$. This demonstrates:

Theorem 1 If CS is convex and $\varepsilon\left(Q_{c}\right)>\frac{n+1}{n}$, then $\lambda_{0}$ is the optimal price.

Theorem 1 provides sufficient (but not necessary) conditions. Its interpretation is that if demand is just a little elastic and satisfies the usual condition that a monopolist absorbs part of a per unit tax, then auction prices are not too high to maximize consumer surplus, even if financing constraints strictly bind. That is, even if the critics of auctions are right that auctions interfere with service deployment, if demand is slightly elastic, consumers prefer the auction revenue to wider deployment and less revenue.

There is at least one commonly-assumed class of demand functions of interest that does not satisfy (12): constant-elasticity demand functions. For this class, CS is concave. When this is the case, it remains true that $\lambda_{B}$ is too low a price for the license (Lemma 2). Yet, as the license price goes above that level, the implied reductions in output become more and more costly in terms of CS. Will it still be optimal to raise the price up to $\lambda_{0}$ ? To answer this question, we now have to look at the slope of CS+R evaluated at $\lambda_{0}$ itself. 
Thus, let us now assume that CS is concave in output, so that CS+R is concave in $\lambda$, for $\lambda>\lambda_{B}$. Concavity of CS+R guarantees that CS+R is increasing in $\lambda<\lambda_{0}$ if it is increasing at $\lambda_{0}$, which occurs when $c-\frac{p}{\varepsilon}>0$ when evaluated at the quantity associated with $\lambda_{0}$. The zero profits condition (10), together with budget binding (3, with equality) implies that

$$
\frac{p}{c}=\frac{B}{B-\lambda}
$$

Therefore,

Theorem 2 If CS is concave, then $\lambda_{0}$ is the optimal price if and only if $\varepsilon \geq \frac{B}{B-\lambda_{0}}$.

Theorem 2 provides a necessary and sufficient condition that relates variables that may readily be estimated: the elasticity of demand at the quantity associated with the auction price, overall expenditures (budget) and license prices. Under the assumption of CS concavity, this allows us to check whether a realized price is excessive. When CS is concave the hypothesis of Lemma 2, that $\varepsilon\left(Q_{c}\right)>\frac{n+1}{n}$, is not sufficient for optimality of $\lambda_{0}$. However one can easily check that it is a necessary condition for $\lambda_{0}$ to be optimal.

\section{Some comments on robustness}

In this section we first analyze the existence and uniqueness of zero-profit prices and its relationship with auction prices. Afterward, we relax the assumption of equal budgets and discuss alternative market models.

Let $K$ represent "output capacity" after any payment for a license. That is, a firm that has budget $B$ and pays the price $\lambda$ has an output capacity equal to $K=\frac{B-\lambda}{c}$. Note that once licenses have been acquired, if firms have capacity in excess of $Q_{c} / n$, then the output in the market will be $Q_{c}$. If firms have a capacity $K<Q_{c} / n$, then output will be $n K$.

Using this notation, we can represent a firm's market profits as a function of capacity

$$
\pi_{m}(K)= \begin{cases}(p(n K)-c) K & \text { if } K \leq \frac{Q_{c}}{n} \\ \left(p\left(Q_{c}\right)-c\right) \frac{Q_{c}}{n} & \text { otherwise }\end{cases}
$$

The function $\pi_{m}$ is concave to the left of $Q_{c}$, and is constant beyond that point. It attains a maximum at the $K$ equal to $\left(1 / \mathrm{n}^{\text {th }}\right.$ of $)$ the monopoly output. We have represented this function as the thick line in Fig. 1.

In Fig. 1 we have also represented several straight lines with slope $-c$. Take any of these and consider its intersection with the horizontal axis. For a firm with a budget given by $c$ times this intersection, this linear function measures for each capacity level the license fee that would leave the firm with that level of capacity. Then, the intersection between the function $\pi_{m}(K)$ and the straight line corresponding to $B$ defines a zero profit license fee when firms have a budget $B$.

Note that $\pi_{m}(K)$ is zero at $\mathrm{K}=0$. Also, we know that the (left) derivative of $\pi_{m}(K)$ with respect to $K$ at $K=Q_{c} / n$ is 


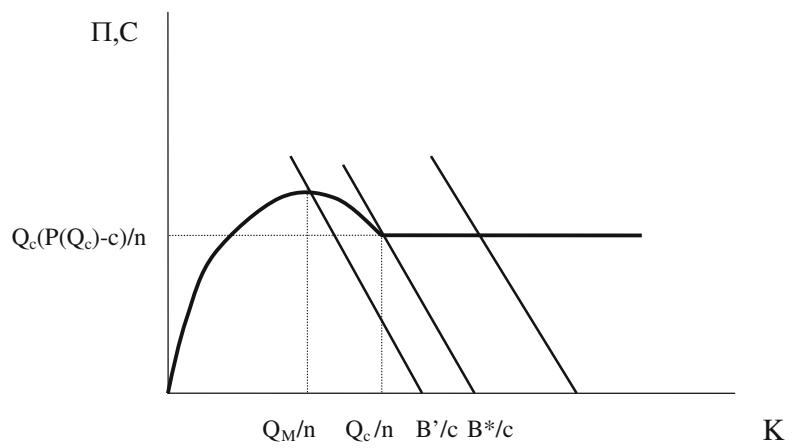

Fig. 1 License price in auctions

$$
p^{\prime}\left(Q_{c}\right) Q_{c}+\left(p\left(Q_{c}\right)-c\right)=p\left(Q_{c}\right)\left[-\frac{1}{\varepsilon}+1\right]-c .
$$

From (6), this is equal to

$$
c\left[\left(-\frac{1}{\varepsilon}+1\right) \frac{n \varepsilon}{n \varepsilon-1}-1\right]=-c \frac{n-1}{n \varepsilon-1} .
$$

This value is negative but larger than $-c$ when $\varepsilon>1$ at $Q_{c}$. Thus, since $\pi_{m}(K)$ is concave in $K$, when $\varepsilon>1$ at $Q_{c}$ there exists one and only one zero-profit capacity/output (and then, one zero-profit $\lambda$ ) for each value of $B$. Therefore, whenever the conditions of Lemma 2 or Theorems 1 and 2 hold there is no ambiguity as to what is the zero-profit license price. ${ }^{11}$

In this model, the relationship between the auction price and the zero-profit price when the latter is unique is trivial. Indeed, there is no private information, and therefore any standard (only winners pay) auction has a unique pure-strategy equilibrium where all firms bid this price. Put in other words, no equilibrium would have a firm paying a negative-profit license price, or a firm not winning a license when some other firm wins one and makes positive profits. Comparative statics for this price with respect to $\mathrm{B}$ are equally straightforward, and are illustrated by Fig. 1. The auction price is (weakly) increasing in the budget.

Next, we discuss asymmetries in budgets. We will refer to the firms by their ranking, from higher to lower, in terms of budgets, and let $B_{i}$ denote firm $i$ 's budget. It is an expositional simplification to assume that no two firms have the same budget. Also, assume that any two firms that obtain a license pay the same price.

In the Appendix (Lemma3) we show that given the license price and any set of winners, only the firms with smallest budgets will be constrained and only if the smallest budget is insufficient to meet the license price and the Cournot quantity.

11 When $\varepsilon<1$ at $Q_{c}$ there may be multiple (up to three) zero-profit prices $\lambda$ for some values of $B$. Intuitively, when license price rise, the budget constraints cause the quantity to fall, and inelastic demand implies that revenues rise. This entails revenues being an increasing function of the license prices, which can offset the increased license price. 
Firms with larger budgets all produce the same, larger output. Since the market price is common to all firms, this means that firms with larger budgets will have larger profits. The immediate implication is that if a firm $j$ is willing to pay some given price for the license in order to compete with some set of $n-1$ other firms in the market, then any other firm $i<j$ should be also willing to pay that price for the license.

A price $\lambda$ will clear the market if it is below the profits of firm $n$ and above the profits of firm $n+1$, both computed in competition with firms 1 through $n-1$. There is an interval of such prices. ${ }^{12}$ Define $\lambda_{0}$ as the largest of all these prices, and $\lambda_{B}$ as the price at which the financing constraint of firm $n$ just binds, when competing against firms 1 through $n-1$.

Assuming that firms 1 through $n$ win a license, we can replicate the major results of Sect. 3. Indeed, for any price lower than $\lambda_{B}, \mathrm{CS}$ is locally independent of $\lambda$, under this construction. Also (14) defines now a lower bound for the slope of CS+R with respect to the license price. To see this, note that the slope of revenues with respect to $\lambda$ is not affected, but the slope of $Q$ with respect to $\lambda$ is lower: When not all firms are financially constrained by the license price, then an increase in this price reduces $Q$ by less than $\frac{n}{c}$. Therefore whenever (14) is positive, at some value of $Q$ (and $P$ ), the slope of CS+R is positive at that value. It follows that Lemma 2 and Theorems 1 and 2 still hold with asymmetric financial constraints. ${ }^{13}$

We have assumed that governments do not value firms' profits. A more general objective function would allow for governments to put some positive weight $\alpha \leq 1$ on firms' profits and perhaps to consider a shadow cost of public funds $\theta>0$. Thus, the objective function of the government would be

$$
\begin{aligned}
W= & C S+\alpha n \Pi+(1+\theta) R \\
= & \int_{0}^{Q}(p(x)-p(Q)) \mathrm{d} x+\alpha n\left(\frac{Q}{n} p(Q)-c \frac{Q}{n}-\lambda\right) \\
& +(1+\theta) n \lambda .
\end{aligned}
$$

Our Lemma 2 and Theorems 1 and 2 still hold with minor changes at least as long as B is not too small. In particular, if B is not lower than $B^{\prime}$ in Fig. 1, the budget at which firms have enough capacity to produce the monopoly output after they pay the zero-profit license price, $\lambda_{0}$. Indeed, note that in such case, and for prices below $\lambda_{0}$, firms' market profits (revenue minus cost) are increasing in $\lambda$ : an increase in the price

\footnotetext{
12 An oral auction, or a sealed bid auction with full information, would tend to pick the low end of this interval.

13 However, it may be in the interest of the government to assign a number of licenses smaller than the technically feasible, selling fewer licenses at higher prices. With symmetric firms, more licenses are generally preferable if more licenses produce a more competitive outcome.
} 
of the license reduces output of all firms and that increases total market profits. Thus, if $\lambda>\lambda_{B}$

$$
\frac{\mathrm{d} W}{\mathrm{~d} \lambda}=\frac{\mathrm{d}(C S+\alpha n \Pi+(1+\theta) R)}{\mathrm{d} \lambda} \geq \frac{n}{c}\left((1+\theta-\alpha) c-\frac{p(Q)}{\varepsilon(Q)}\right) .
$$

The right hand side of (16) is a lower bound on the slope of the objective function with respect to $\lambda$. Compare (16) with (14). Now, a sufficient condition for optimal prices to be strictly larger than $\lambda_{B}$ is that $(1+\theta-\alpha) c-\frac{p}{\varepsilon}>0$. Repeating the same arguments as in Sect. 3, the implication is that the sufficient condition for the optimal license price to be larger than $\lambda_{B}$ (Lemma2) is $\varepsilon\left(Q_{c}\right)>\frac{n+(1+\theta-\alpha)}{n(1+\theta-\alpha)}$. Likewise, the right hand side of (16) is still increasing in $\lambda$ when CS is convex in $\lambda$ and decreasing when CS is concave. Thus, when CS is convex, the same condition is sufficient for $\lambda_{0}$ to be optimal (Theorem 1). Finally, (15) still holds, so that if CS is concave a sufficient condition for $\lambda_{0}$ to be optimal is that $\varepsilon \geq \frac{B}{\left(B-\lambda_{0}\right)(1+\theta-\alpha)}$ (Theorem 2).

Summing up, a higher value of license revenues favors auctions, while value on firm profits disfavors auctions. Moderate levels of each do not affect the basic conclusions of our analysis and enter simply into the calculations. ${ }^{14}$

We have modeled the market for telecommunications as a simple Cournot market. It may be argued that telecommunications are characterized by network externalities, which may render reductions in output more costly. For instance, one could postulate, as in Amir and Lazzati (2009), a demand function $P(Q ; Z)$, where $Z$ is the expected size of total output (network), ${ }^{15}$ and assume that $P_{1}<0$, and $P_{2}>0$, where $P_{i}$ represents the partial derivative of $P$ with respect to the $i$ th argument. ${ }^{16}$ Moreover, assume that network effects do not domiante, so that $P_{1}+P_{2}<0$. In equilibrium, $Q=Z$.

Let $A=\frac{P_{1}}{P_{1}+P_{2}}>1$. Then, the condition of Lemma 2 becomes $\varepsilon\left(Q_{c}\right)>\frac{\frac{n}{A}+1}{n}$, where now $\varepsilon(Q)=\left.\frac{-p(Q ; Z)}{Q} \frac{1}{P_{1}}\right|_{Q=Z}$, i.e., the elasticity of demand for a fixed expected total output. ${ }^{17}$ Therefore, the sufficient conditions for auctions to be optimal (when the consumer surplus is convex) are even weaker, when we consider the effects of externalities.

Finally, we should note that assuming price competition would not have an effect on the qualitative results, as is sometimes the case in oligopoly models. Indeed, as long as firms are constrained and have a total capacity $n k=Q$ below the competitive quantity, in a Bertrand equilibrium all firms set prices equal to $P(Q)$. Then, Eq. 15 still holds, except that $\lambda_{B}$ should now be defined as the license price that leaves firms with just enough resources to produce the competitive quantity, instead of the Cournot

\footnotetext{
14 Of course, if the shadow cost of public funds is 0 and governments put equal weight to profits and consumer surplus, then the optimal price would be one where firms are not budget constrained. This may even imply a subsidy to operators.

$15 \mathrm{Z}$ may be a measure of network quality, when it is the size of total industry investment what matters for consumer, and not individual firm investment.

16 Amir and Lazzati (2009) show that under mild conditions a Cournot equilibrium exists, although some additional assumptions are required for uniqueness.

17 This would be the elasticity that would be measured by most empirical tests.
} 
quantity. Thus, Theorem 2 holds without changes. Theorem 1 also holds with only substituting the competitive quantity for $Q_{c}$. It is also straightforward to show that whenever the elasticity is above 1 at the competitive quantity, $\lambda_{0}$ is uniquely defined in this alternative setting, and then $\lambda_{0}$ is the auction price. The only caveat here is that under these assumptions, firms would be capacity constrained at the auction price if and only if their budget constrains also at zero license prices. In any case, the conclusion is unchanged: if demand is not very inelastic, auctions maximize the sum of consumer surplus and revenues even when they reduce output.

We have modeled the firms as setting quantities; in some circumstances investments set quality rather than quantity. For the United States, where some areas lack cell coverage, marginal investments may extend coverage to new areas and therefore increase quality for existing customers who are roaming, while increasing quantity by offering service to new customers. When investment is used to put cell towers closer together, a greater capacity of calls can be carried simultaneously and this corresponds closely to the model's assumptions. The case of $3 \mathrm{G}$ represents a mix —an increase in the quality of data transmission but increases in quantity of voice and data. Given that quality is often modeled as a kind of quantity, the present model has a natural, if somewhat strained, quality interpretation.

\section{The European 3G experience}

Licenses for spectrum intended for $3 \mathrm{G}$ (third generation) cellular telephony usage were assigned beginning in March 2000 with Spain. ${ }^{18}$ The first auction of $3 \mathrm{G}$ licenses took place in the United Kingdom and ended in April 2000. The four incumbent GSM operators (Vodafone, BT's O2, France Telecom's Orange, and T-Mobile) and a new entrant, Hutchison, each won a license. Prices were considered astronomically high, because the prices exceeded the prices for the US PCS spectrum, in spite of the US spectrum having fewer constraints on usage. About the same time as the UK auctions, the stock price index of telecoms started declining (see EC 2002, exhibit 26). By the time the next auction took place in the Netherlands, only three months later, telecom firms had lost about $25 \%$ of their equity value. This time, each of the five incumbents (KPN, O2, T-Mobile, Dutchtone and Orange) won a license. A month later, when the German auction closed, telecom share prices had fallen even further, to about two-thirds of their March 2000 value. In Germany 6 licenses were sold. ${ }^{19}$ All of the licenses went to incumbents or affiliates of major European firms. The next auction took place in Italy, in October 2000. By then, the stock market index of European Telco's had already lost more than $40 \%$ of its value, as compared to a loss by the American counterparts of about $25 \%$ during the same period.

Licenses included obligations to deploy $3 \mathrm{G}$ networks with minimum coverage requirements and deadlines. For instance, license holders in the UK were required to have a network in place that covered $80 \%$ of the UK population by the end of 2007 .

\footnotetext{
18 For a description and analysis of the recent regulation of telephony in Europe, see Grzybowsky (2005).

19 Twelve blocks were on sale, and each firm could buy two or three of these blocks. Thus, the number of licenses was endogenously determined.
} 
In Sweden, the conditions of the beauty contest pushed this to $99.98 \%$ of the population by the end of 2003. In the Netherlands, the requirements included coverage of at least $60 \%$ of the population by 2007 , and in Germany $25 \%$ of the population by the end of 2003 and $50 \%$ by the end of 2005 .

Immediately after the first wave of license allocations as the year 2000 ended, the mood in the industry changed. As some say, the internet and telecom bubble burst. The prospect of profitable $3 \mathrm{G}$ services receded. If only a few months earlier the market was in the peak of the optimism about the telecom industry, by the end of 2000 and beginning of 2001 the articles in the financial press were filled with comments about the struggling of telecom firms with debt crises. The debt taken to finance the acquisition of licenses was often identified as an important contributory factor of the telecom debt crisis. With the equity markets hostile to telecoms, most European telecoms borrowed a substantial amount of money. ${ }^{20}$

In this landscape of diminished expectations, the launching of $3 \mathrm{G}$ services was delayed. In fact, with the unsuccessful exception of Hutchison's 3, the launching of 3G services did not begin until mid-2004. Mobilcom and Quam in Germany and Orange in Sweden had failed to meet their roll-out obligations and consequently had to return their licenses.

In all countries, firms lobbied for delays in their $3 \mathrm{G}$ coverage obligations, and in most places they succeeded. Sweden allowed a year extension on the requirement of (virtually) full population coverage (from the end of 2003 to the end of 2004). Even this extended deadline was not met. In addition, operators received permission to sharing their networks, so that the originally envisioned structure of one independent, competing network per license was lost. Thus, network sharing agreements among carriers were approved by national governments, including the UK, Sweden, Germany, and the Netherlands. As of February 2005, population coverage of $3 \mathrm{G}$ networks had reached only $85 \%$ in Sweden, $75 \%$ in the UK, and less than $60 \%$ in the rest of Europe.

The demand elasticity is a critical input to the theory. Earlier studies in wireless telephony obtain elasticity estimates in the range $0.50-1.0 .{ }^{21}$ However, early adopters of cellular telephony probably had relatively inelastic demand, so that demand at lower prices is likely substantially more elastic than these estimates suggest. For instance, using data from 1999 to 2001, Ingraham and Sidak (2004) estimate wireless services price elasticity in the range 1.12 and 1.29 . In addition, the demand for $3 \mathrm{G}$ services such as video and gaming is likely more elastic than wireless telephony, because the luxury component is larger. Wallenius and Hämäläinen (2002) estimate the elasticity of demand for $3 \mathrm{G}$ services to be in the range 1.4-1.7, although their source is not identified. One could argue that the elasticity of the demand for $3 \mathrm{G}$ services can be better estimated by measures of the elasticity of internet access than by measures of telephony. The former are consistently higher, typically above 2 (see, for instance, Goolsbee 2006). In a recent study with Finish data obtained from a real-world experiment, Gao et al. (2005) estimate the per-minute price elasticity of wireless internet access to range from 1.78 to 2.28 (length of connection) and around 1.59 (number

\footnotetext{
20 The Economist, January 25, 2001.

21 See, for instance Rodini et al. (2002) or Hausman (1999, 2000).
} 
of connections). Estimating the demand elasticity is made more challenging by the plethora of services being introduced and by increasing differentiation of the product.

If the demand elasticity were 1.5 , then auction prices would maximize consumer surplus (including license revenues) for all if license prices accounted for less than a third of the firms' budgets, even if the firms were financially constrained and consumer surplus concave. If, as in the usually assumed case, consumer surplus is a convex function of quantity, then at an elasticity of 1.5, two licenses is sufficient to insure that auctioning is optimal.

A proxy for the firms' budgets is the sum of estimated cost of deploying a $3 \mathrm{G}$ network plus the license fee. ${ }^{22}$ Taking Western Europe as a whole, ${ }^{23}$ the total cost of building networks for all licensees (in the 2000-01 sales) has been estimated at 140B $€$, whereas total cost of licenses was $120 \mathrm{~B} €,{ }^{24}$ a ratio of license to total cost (network plus licenses) of almost $1 / 2$. However, most of the cost of licenses is accounted for by the British and German auctions, which raised total of $86 \mathrm{~B} €$. In the UK, license prices total $36 \mathrm{~B} €$, compared to an estimated $21 \mathrm{~B} €$ needed in network investment. License fees appear close to two-thirds of the total cost (license plus network) of deploying $3 \mathrm{G}$ services. Similarly, in Germany the license cost was 50B $€$ and estimated cost of the network only $34 \mathrm{~B} €$, so that license fee accounted for $60 \%$ of deployment cost. ${ }^{25}$ In the rest of the countries that used auctions to assign licenses, the ratio of license fees to total estimated costs ranged from $12 \%$ in Greece to $34 \%$ in the Netherlands. ${ }^{26}$

The formula in Theorem 2 permits calculating the elasticity necessary to justify auction prices, assuming the financing constraints bind. ${ }^{27}$ If CS is concave, auction prices maximized consumer surplus in the UK only if the elasticity of demand exceeded 2.7. In Germany, the critical elasticity is about 2.5. These elasticities exceed most estimates for the elasticity of demand for $3 \mathrm{G}$ services, suggesting that the prices perhaps were too high to maximize consumer surplus, unless financing constraints for the firms did not bind or consumer surplus is convex. In other countries, however, the critical elasticity is 1.5 or less, suggesting that an auction maximized consumer surplus no matter what assumption is placed on consumer surplus.

\footnotetext{
22 This figure ignores marketing and other costs of operating a network, but also ignores network sharing. As it treats the cost of building a network as fixed, it tends to over-estimate the budget.

23 All figures used in this paragraph are taken from EC (2002).

24 Our source is EC (2002). The figures refer to $3 \mathrm{G}$ network deployment, and do not include upgrades and replacement investment for $2 \mathrm{G}$ networks. The estimated total investment in this category needed for the period $2000-2015$ is $90 \mathrm{~B} €$.

25 These numbers are corroborated by the experience of $\mathrm{O} 2$, the originally BT mobile company. It is estimated that it spent a total $4 \mathrm{~B} £$ (approx. $6 \mathrm{~B} €$ ) in building its $3 \mathrm{G}$ networks, mainly in the UK and Germany. It spent around $15 \mathrm{~B} €$ acquiring its British and German licenses. License fees in both markets represented more than $70 \%$ of its estimated budget (network cost plus license fees) for both markets.

26 A referee suggested an interesting view of the European auctions. If there are strong synergies across nations, later auctions will have little competition beyond early winners and hence sell at low prices. Consequently early auctions command a premium over value due to earnings in subsequent auctions. In this case the overall European prices and costs would yield a better critical elastisticity.

27 Note that Theorem 2 references the elasticity at the zero profits or auction price, so that the relevant comparison is to the prevailing elasticity estimates, at least in the countries that auctioned the licenses.
} 
Given the problems that telecom firms faced with borrowing in the 2001-2005 period, it seems plausible that the firms were financially constrained, but, were they? Financing constraints ought to create a negative correlation between license prices and build-out. In the countries with the two highest prices per capita, the UK and Germany, services were deployed relatively quickly, but services were rapidly rolled out in Luxemborg and Sweden as well, which had low prices. Because the nations with the highest per capita demand will attract higher auction prices, higher budgets and faster deployment, assessing the existence of financing constraints empirically is challenging. Moreover, the effect of financing constraints is generally to slow deployment, rather than reduce it permanently, so that the time of allocation is also important in the attempt to empirically assess financing constraints. Given the small number of countries, and the possibility of endogeneity in the choice of allocation method, an attempt to empirically assess the existence of financing constraints is a daunting task.

\section{Conclusion}

Both experience with telecommunications companies and corporate finance research indicates that financing constraints are a fact of life in many bidding contexts. In principle, frequent company complaints that high auction prices prevented the rapid rollout of services could have merit. The effect of financing constraints on the deployment of services was examined in the context of a model of hard budgets. Evaluation of the effect of auction prices hinges on relatively inelastic demand, and auctions are optimal even when the firms are financially constrained, provided the auction price is not too large a fraction of the firms' resources.

Demand for $3 \mathrm{G}$ services is probably elastic, as the most relevant evidence suggests. In that case, and even given hard financing constraints, in most countries the auction prices appear to maximize consumer surplus, understood as including license revenue. Thus auctions appear to be the best way to allocate the licenses. According to the theory and proposed demand elasticities, only in the U.K. and Germany could some doubts remain as to whether auction prices constrain the rollout of services beyond what is optimal, and then only if consumer surplus is concave.

In the main body of the paper we have assumed homogeneous quantity competition. In our view, the Cournot model captures salient features of the cellular communication market. Capacity is determined by deployment of cell towers in most regions and additional capacity requires either more towers (smaller cells) or more spectrum. As with Kreps and Scheinkman (1983), pricing decisions are made long after capacity choices. Thus, the Cournot model seems like a reasonable starting point for an analysis of auctions. This is also the main argument that Grzybowski (2005), among others, advance for analyzing this industry in a Cournot model. With that said, however, the likely effect of increased prices is not a permanent decrease in capacity but a temporary decrease in capacity. Our model can be interpreted as one in which delay is very costly (discount factor close to zero). Consequently, our assumptions exaggerate the effects of a service reduction, which makes our finding that auctions are optimal stronger. Nevertheless, it would certainly be worthwhile preparing a formal model of the 
dynamic problem. A simplification might involve a threat of bankruptcy, as auctions should exacerbate the risk of bankruptcy.

Auctions have an additional advantage obscured by the symmetry of the model: auctions select the efficient service providers. Even if demand is relatively inelastic, it may be desirable to auction in order to select efficiently. However, in such a setting, auctions could have a perverse effect if the most efficient firms face relatively tighter financing constraints, because auctions favor both the efficiency and large budgets. Nevertheless, we expect that the advantages of auctions over random selection are greater when firms are differentiated than in our simple model. Finally, we have analyzed only license price decisions. Beauty contest advocates argue that from the consumer surplus point of view there is a procedure that improves upon price competition: making firms commit to the extent and speed of deployment. However, as the $3 \mathrm{G}$ European experience has shown, commitments to future investment may be renegotiated.

Acknowledgements Burguet acknowledges partial financial support from BGSE Research Network and the Generalitat de Catalunya, and from the Spanish Ministry of Education and Science, project SEJ200501427 and ECO2008-01850. We thank two knowledgeable referees for assistance.

Open Access This article is distributed under the terms of the Creative Commons Attribution Noncommercial License which permits any noncommercial use, distribution, and reproduction in any medium, provided the original author(s) and source are credited.

\section{Appendix}

Proof of Lemma 1 For the moment, ignore the financing constraint. Fix the output of other firms at $Q_{-i}$, so that profits are

$$
\pi=p\left(q+Q_{-i}\right) q-c q-\lambda .
$$

If the constraint does not bind, the second derivative of profits is

$$
\frac{\partial^{2} \pi}{(\partial q)^{2}}=q p^{\prime \prime}\left(q+Q_{-i}\right)+2 p^{\prime}\left(q+Q_{-i}\right) .
$$

If $p^{\prime \prime}\left(q+Q_{-i}\right)<0, \frac{\partial^{2} \pi}{(\partial q)^{2}}<0$ since $p$ is a demand curve. If $p^{\prime \prime}\left(q+Q_{-i}\right)>0$, $\frac{\partial^{2} \pi}{(\partial q)^{2}}=q p^{\prime \prime}\left(q+Q_{-i}\right)+2 p^{\prime}\left(q+Q_{-i}\right)<\left(q+Q_{-i}\right) p^{\prime \prime}\left(q+Q_{-i}\right)+2 p^{\prime}\left(q+Q_{-i}\right)<0$ by (2). Either way, $\pi$ is globally concave, so the Kuhn-Tucker condition characterizes a maximum.

The Kuhn-Tucker condition is

$$
\frac{\partial \pi}{\partial q}=q p^{\prime}\left(q+Q_{-i}\right)+p\left(q+Q_{-i}\right)-c \begin{cases}=0 & \text { if } c q+\lambda<B \\ \geq 0 & \text { if } c q+\lambda=B\end{cases}
$$


or

$$
q p^{\prime}(Q)+p(Q)-c \begin{cases}=0 & \text { if } c q+\lambda<B \\ \geq 0 & \text { if } c q+\lambda=B\end{cases}
$$

or

$$
p(Q)\left(1-\frac{q}{Q} \frac{1}{\varepsilon(Q)}\right)-c \begin{cases}=0 & \text { if } c q+\lambda<B \\ \geq 0 & \text { if } c q+\lambda=B\end{cases}
$$

Note that, if firm $i$ is constrained, then any firm producing the quantity $q$ less than $q_{i}$ satisfies

$$
p(Q)\left(1-\frac{q}{Q} \frac{1}{\varepsilon(Q)}\right)-c>p(Q)\left(1-\frac{q_{i}}{Q} \frac{1}{\varepsilon(Q)}\right)-c \geq 0 .
$$

Thus, if one firm is constrained, they are all constrained. That is, either no firm, or all firms, are constrained. Consequently, (2) entails that any equilibrium is symmetric, and satisfies

$$
p(Q)\left(1-\frac{1}{n \varepsilon(Q)}\right)-c\left\{\begin{array}{ll}
=0 & \text { if } c Q / n+\lambda<B \\
\geq 0 & \text { if } c Q / n+\lambda=B
\end{array} .\right.
$$

Note that

$$
\begin{aligned}
\frac{\mathrm{d}}{\mathrm{d} Q} p(Q)\left(1-\frac{1}{n \varepsilon(Q)}\right)-c & =\frac{1}{n} \frac{\mathrm{d}}{\mathrm{d} Q}\left(n p(Q)+Q p^{\prime}(Q)\right) \\
& =\frac{1}{n}\left((n+1) p^{\prime}(Q)+Q p^{\prime \prime}(Q)\right) \\
& =\frac{1}{n}\left((n-1) p^{\prime}(Q)+2 p^{\prime}(Q)+Q p^{\prime \prime}(Q)\right) \\
& \leq \frac{1}{n}\left(2 p^{\prime}(Q)+Q p^{\prime \prime}(Q)\right) \leq 0,
\end{aligned}
$$

by (2).

Thus, there is a unique Cournot equilibrium.

Lemma 3 For any vector $\left(B_{1}, B_{2}, \ldots, B_{n}\right)$ of budgets, and license price $\lambda$ there is $a$ unique pure strategy equilibrium output $\left(q_{1}, q_{2}, \ldots, q_{n}\right)$. If $B_{n}-\lambda>c Q_{c} / n$, then $q_{i}=Q_{c} / n$ for all $i$. If $B_{j}-\lambda>c Q_{c} / n>B_{j+1}-\lambda$ for some $j<n$, then there exists $k \geq j$ such that $c q_{i}=B_{i}-\lambda$ for all $i>k, q_{i}=q$ for all $i<k$ for some value $q>Q_{c} / n$, and $Q<Q_{c}$. 
Proof of Lemma 3 As in the proof of Lemma 1, $\pi$ is globally concave, so the KuhnTucker condition characterizes a maximum:

$$
\frac{\partial \pi}{\partial q}=q p^{\prime}\left(q+Q_{-i}\right)+p\left(q+Q_{-i}\right)-c\left\{\begin{array}{l}
=0 \text { if } c q+\lambda<B \\
\geq 0 \text { if } c q+\lambda=B
\end{array}\right.
$$

or

$$
p(Q)\left(1-\frac{q}{Q} \frac{1}{\varepsilon(Q)}\right)-c\left\{\begin{array}{l}
=0 \text { if } c q+\lambda<B \\
\geq 0 \text { if } c q+\lambda=B
\end{array}\right.
$$

Assume $\mathrm{B}_{n}-\lambda>\mathrm{cQ}_{c} / n$. Then, if some firm $\mathrm{i}$ is constrained, $q_{i}>\mathrm{Q}_{c} / n$ and any firm producing the quantity $q$ less than $q_{i}$ satisfies

$$
p(Q)\left(1-\frac{q}{Q} \frac{1}{\varepsilon(Q)}\right)-c>p(Q)\left(1-\frac{q_{i}}{Q} \frac{1}{\varepsilon(Q)}\right)-c \geq 0 .
$$

Thus, if firm $\mathrm{i}$ is constrained, every firm $\mathrm{j}$ produces at least the minimum of $\mathrm{B}_{j}-\lambda$ and $q_{i}$, which means that $\mathrm{Q}>\mathrm{Q}_{c}$. But this contradicts (2). Thus, $\mathrm{B}_{n}-\lambda>\mathrm{cQ}_{c} / \mathrm{n}$ no firm is constrained and then the only equilibrium is $q_{i}=\mathrm{Q}_{c} / \mathrm{n}$ for all $\mathrm{i}$.

Now, assume $\mathrm{B}_{j}-\lambda>\mathrm{cQ}_{c} / \mathrm{n}>\mathrm{B}_{j+1}-\lambda$ for some $\mathrm{j}<\mathrm{n}$. First note that $\mathrm{Q}<\mathrm{Q}_{c}$ in any equilibrium, in this case. Indeed, otherwise at least one firm i produces more than $\mathrm{Q}_{c} / \mathrm{n}$, and then the Kuhn-Tucker condition is violated for this firm. This immediately implies that $\mathrm{c} q_{i}=B_{i}-\lambda$ for all $\mathrm{i}>\mathrm{j}$, and $\mathrm{Q}<\mathrm{Q}_{c}$.

Given a set of firms that are constrained, and therefore their aggregate output, consider the residual demand for other firms. This satisfies the same conditions of the original demand function. Thus, there exists a unique, symmetric output equilibrium for these firms, as in Lemma 1.

Thus, to complete the proof of Lemma 3 we only need to show that there is a unique set of constrained firms. Assume there is some $\mathrm{k}$ so that

$$
\frac{\partial \pi}{\partial q}=q p^{\prime}\left(q_{i}+Q_{-i}\right)+p\left(q_{i}+Q_{-i}\right)-c \begin{cases}=0 & \text { if } i<k \\ \geq 0 & \text { if } i \geq k\end{cases}
$$

and

$$
q_{i}= \begin{cases}q & \text { if } i<k \\ \frac{B_{i}-\lambda}{c} & \text { if } i \geq k\end{cases}
$$

for some value q. Now assume that for some $k^{\prime}<k$, we have some other vector of outputs for $i \geq k, q_{i}^{\prime}=\frac{B_{i}-\pi}{c}, q_{i}^{\prime}=q^{\prime}$ for $i<k^{\prime}$ satisfying the Kuhn-Tucker condition. Note that $q_{k^{\prime}}^{\prime}=\frac{B_{i}-\lambda}{c}>q_{k \prime}$. Given global concavity of $\pi$, this implies both $Q_{-k^{\prime}}^{\prime}<Q_{-k^{\prime}}$ so that $q>q^{\prime}$ ( since $q_{i} \leq q_{i}^{\prime}$ for all $i \geq k^{\prime}$ ) and then $Q_{-1}^{\prime}>Q_{-1}$. Next 
we show that this implies that $Q^{\prime}>Q$. Indeed, define $\tilde{q}=Q^{\prime}-Q_{-1}$. If $Q^{\prime} \leq Q$, then $\tilde{q}+Q_{-1} \leq Q$, so that $\tilde{q} \leq q$. Then, from the Kuhn-Tucker conditions, we have that

$$
\tilde{q} p^{\prime}\left(\tilde{q}+Q_{-1}\right)+p\left(\tilde{q}+Q_{-1}\right)-c=\tilde{q} p^{\prime}\left(Q^{\prime}\right)+p\left(Q^{\prime}\right)-c \geq 0
$$

and then we conclude that $\tilde{q} \leq q^{\prime}$ as well. Now, since

$$
q^{\prime}+Q_{-1}^{\prime}=Q^{\prime}=\tilde{q}+Q_{-1},
$$

this implies that $Q_{-1}^{\prime} \leq Q_{-1}$. This contradiction proves that $Q^{\prime}>Q$.

Then,

$$
Q_{-k^{\prime}}^{\prime}=Q^{\prime}-\frac{B_{i}-\lambda}{c}>Q-\frac{B_{i}-\lambda}{c}>Q-q_{k^{\prime}}=Q-q
$$

and then concavity of $\pi$ and the Kuhn-Tucker conditions for the equilibrium resulting in output $Q^{\prime}$ contradicts the Kuhn-Tucker condition for the equilibrium resulting in output $\mathrm{Q}$, i.e.,

$$
q p^{\prime}\left(q+Q_{k^{\prime}}\right)+p\left(q+Q_{k^{\prime}}\right)-c=0 \text {. }
$$

This contradiction shows that there exists only one equilibrium for each vector of budgets.

\section{References}

Amir, R., \& Lazzati, N. (2009). Network effects, market structure and industry performance, mimeo, University of Arizona.

Benoit, J. P., \& Krishna, V. (2001). Multiple-object auctions with budget constrained bidders. The Review of Economic Studies, 68(1), 155-179.

Che,Y.-K., \& Gale, I. (1998). Standard auctions with financially constrained bidders. Review of Economic Studies, 65, 1-22.

Clementi, G. L., \& Hopenhayn, H. (2006). A theory of financing constraints and firm dynamics. The Quarterly Journal of Economics, 121, 229-265.

Commission of the European Communities. (2002). Communication from the Commission to the Council, the European Parliament, The Economic and Social Committee, and the Committee of the Regions: Towards the full roll-out of third generation mobile services. Brussels 11.6.2002, COM 301 Final.

European Commission. (2002). Comparative assessment of the licensing regimes for $3 G$ mobile communications in the European Union and their impact on the mobile communications sector, final report. Brussels.

Fazzari, S., \& Athey, M. J. (1987). Asymmetric information, financing constraints, and investment. Review of Economics and Statistics, 69(3), 481-487.

Fazzari, S., Hubbard, R. G., \& Petersen, B. C. (1988). Financing constraints and corporate investment. Brookings Papers on Economic Activity, 1988(1), 141-206.

Fazzari, S., \& Petersen, B. (1993). Working capital and fixed investrment: New evidence on financing constraints. Rand Journal of Economics, 24(3), 328-342.

Gao, M., Hyytinen, A., \& Toivanen, O. (2005). Demand for mobile internet: Evidence from a real-world pricing experiment, HECER discussion paper No. 43. University of Helsinki.

Goolsbee, A. (2006). The value of broadband and the deadweight loss of taxing new technology, mimeo, University of Chicago. 
Greenwald, B., Stiglitz, J. E., \& Weiss, A. (1984). Informational imperfections in the capital market and macroeconomic fluctuations. American Economic Review Papers and Proceedings, 74, 194-199.

Greenwood, J., \& McAfee, R. P. (1991). Externalities and asymmetric information. Quarterly Journal of Economics, CVI, (1), 103-121.

Grzybowsky, L. (2005). Regulation of mobile telephony across the European union: An empirical analysis. Journal of Regulatory Economics, 28(1), 47-67.

Haan, M. A., \& Toolsema, L. A. (2003). License auctions when winning bids are financed through debt. mimeo, U. of Groningen.

Hart, O., \& Moore, J. (1995). Debt and seniority: An analysis of the role of hard claims in constraining management. American Economic Review, 85(3), 567-585.

Hausman, J. (1999). Cellular telephone, new products, and the CPI. Journal of Business and Economic Statistics, 17(2), 188-194.

Hausman, J. (2000). Efficiency effects on the U.S. economy from wireless taxation. National Tax Journal, 53(2), 733-742.

Ingraham, A., \& Sidak, G. (2004). Do states tax wireless services inefficiently? Evidence on the price elasticity of demand. Virginia Tax Review, 24(2), 249-261.

Jensen, M. C. (1986). Agency costs of free cash flow, corporate finance and takeovers. American Economic Review Papers and Proceedings, 76(2), 323-329.

Klemperer, P. (2002). How (not) to run auctions: The European $3 \mathrm{G}$ telecom auctions. European Economic Review, 46, 829-845.

Kreps, D., \& Scheinkman, J. (1983). Quantity precommitment and Bertrand competition yield Cournot outcomes. Bell Journal of Economics, 14, 326-337.

Lewis, T., \& Sappington, D. E. M. (1989a). Inflexible rules in incentive problems. American Economic Review, 79(1), 69-84.

Lewis, T., \& Sappington, D. E. M. (1989b). Countervailing incentives in agency problems. Journal of Economic Theory, 49 294-313.

Love, I. (2003). Financial development and financing constraints: New evidence from the structural investment model. Review of Financial Studies, 16(3), 765-791.

McCleland, S. (2003). Telecom meltdown: Don't blame us, say forecasters. BusinessWeek online, October 13.

Myers, S., \& Majluf, N. S. (1984). Corporate financing and investment decisions when firms have information that investors do not have. Journal of Financial Economics, 13, 187-221.

Pitchik, C., \& Schotter, A. (1988). Perfect equilibrium in budget-constrained sequential auctions: An experimental study. Rand Journal of Economics, 19, 363-88.

Rodini, M., Ward, M. R., \& Woroch, G. A. (2002). Going mobile: Substitutability between fixed and mobile access. Haas School of Business, Center for Research on Telecommunications Policy Working Paper CRTP-58.

Salant, D. (1997). Up in the air: GTE's experience in the MTA auction for personal communication services licenses. Journal of Economics \& Management Strategy, 6(3), 549-572.

Stiglitz, J. E., \& Weiss, A. (1981). Credit rationing in markets with imperfect information. American Economic Review, 71, 393-410.

Wallenius, E., \& Hämäläinen, T. (2002). Pricing model for 3G/4G networks. The 13th IEEE international symposium on personal, Indoor and Mobile Radio Communications, 1, 187-191.

Whited, T. (1992). Debt, liquidity constraints, and corporate investment: Evidence from panel data. Journal of Finance, 47, 1425-1460. 